\title{
Synthesis and Characterization of Biodegradable Thiolated Chitosan Nanoparticles as Targeted Drug Delivery System
}

\author{
Mohammad Reza Saboktakin ${ }^{1,2 *}$, Roya M.Tabatabaie ${ }^{1}$, Abel Maharramov $^{2}$ and Mohammad Ali Ramazanov ${ }^{2}$
}

${ }^{1}$ Nanostructured Materials synthesis Lab, International Research Institute of Arian Chemie Gostar, Tabriz, Iran

${ }^{2}$ Nanostructured Materials synthesis Lab, Baku State University, Baku, Azerbaijan

\begin{abstract}
The main objectives of our study were to prepare and evaluate a biodegradable nanoparticulate system of Letrozole (LTZ) intended for breast cancer therapy. LTZ loaded thiolated chitosan (TCS) nanoparticles were prepared by emulsion-solvent evaporation method. LTZ loaded TCS nanoaprticles were characterized by infrared spectra, drug entrapment efficiency and in vitro release. The system sustained release of LTZ significantly and further investigation could exhibit its potential usefulness in breast cancer therapy. The nanoparticles of LTZ prepared from TCS - may represent a useful approach for targeting its release at its site of absorption, sustaining its release.
\end{abstract}

Keywords: TCS; Biodegradable; Nanoparticles; LTZ; Breast Cancer therapy

\section{Introduction}

TCS which are gaining popularity because of their high mucoadhesiveness and extended drug release properties [1]. The derivatization of the primary amino groups of chitosan (CS) with coupling reagents bearing thiol fuctions leads to the formation of TCS [1]. The use of LTZ, which inhibits estrogen biosynthesis, is an attractive treatment for postmenopausal women with hormone - dependent breast cancer [2]. Since the early 1980s, the concept of mucoadhesion has gained considerable interest in pharmaceutical technology. If might open the door for novel, highly efficient dosage forms especially for oral drug delivery [3]. The most important goal of cancer chemotherapy is to minimize the exposure of normal tissues to drugs while maintaining their therapeutic concentration in tumors. Interestingly, nanoparticle (NPs) exhibits a significant tendency to accumulate in a number of tumors after intravenous injection [4]. Hence, uptake and consequently bioavailability of the drug may be increased and frequency of dosing reduced with the result that patient compliance is improved [5,6]. Various natural and synthetic polymers have been discovered as mucoadhesive excipients. Their mucoadhesive properties can be explained by their interaction with the glycoproteins of the mucus based mainly on non-covalent bonds such as ionic interactions, hydrogen bonds and vander Waals forces $[7,8]$. The biopolymer CS is obtained by alkaline deacetylation of chitin which one of the most abundant polysaccharides in nature [9]. Shell wastes of shrimp, lobster and crab are the main industrial sources of chitin [10]. The primary amino group accounts for the possibility of relatively easy chemical modification of CS and salt formation with acids. At acidic $\mathrm{P}^{\mathrm{H}}$, the amino groups are protonated, which promotes solubility, whereas CS is insoluble at alkaline and neutral $\mathrm{P}^{\mathrm{H}}[11,12]$. Because of its favorable properties, such as enzymatic biodegradability, non-toxicity and biocompatibility CS has received considerable attention as a novel excipient in drug delivery systems, and has been included in the European Pharmacopoeia since 2002 [13]. The administration of nanoparticles will also provide the advantage of facilitating their injection through standard infiltration needles. So far, there was one published literature on LTZ nanoparticles prepared by direct precipitation technique [14]. Recently, it has been shown that polymers with thiol groups provide much higher adhesive properties than polymers generally considered to be mucoadhesive [15]. To increase patient complicance, to overcome the undesirable side effects, LTZ could be entrapped into biodegradable nanoparticles for sustained delivery so that it can inhibit estrogen biosynthesis for a prolonged time by virtue of increased local concentration of the drug at the receptor site $[16,17]$. To date, three different thiolated CS derivatives have been synthesized: CS-thioglycolic acid conjugates, CS-cysteine conjugates and chitosan-4-thio-butyl-amidine (CS-TBA) conjugates [18]. These TCS have numerous advantageous features in comparison to unmodified CS, such as significantly improved mucoadhesive and permeation enhancing properties [19]. The strong cohesive properties of TCS make them highly suitable excipients for controlled drug release dosage forms [20]. We have prepared LTZ-loaded TCS nanoparticles (LTZ-TCS-NPs) by emulsion solvent evaporation technique to obtain smaller particle size with high entrapment efficiency and sustained release profile. Particle size, morphology, entrapment efficiency, drug - polymer interaction and in vitro release of LTZ- TCS-NPs were evaluated. The influence of $\%$ of drug (relation to polymer mass) on formulation performance including particle size, entrapment efficiency and in vitro release was investigated.

\section{Materials and Methods}

\section{Materials}

The grade of CS used in this study was purchased from Aldrich (St Louis, MO) (viscosity, 275.9 cps, degree of deacetylation [dd], 80.5\%). LTZ was provided by Aldrich Pharmaceuticals. All reagents and chemicals used for chromatography (HPLC) grade. All other chemicals and organic solvents were of reagent grade.

\section{Instruments}

Analytical TLCs were run on commercial Merck Co. (Germany) plates coated with silica gel GF250 $(0.25 \mathrm{~mm}$ thick). Fourier transfer infrared (FT-IR, Bruker, Germany) spectroscopy was used to identified

*Corresponding author: Mohammad Reza Saboktakin, International Research Institute of Arian Chemie Gostar, Tabriz, Iran, Tel/Fax: +00984116694803; E-mail: saboktakin123@yahoo.com

\section{Received May 20, 2011; Accepted July 09, 2011; Published July 12, 2011}

Citation: Saboktakin MR, Tabatabaie RM, Maharramov A, Ramazanov MA (2011) Synthesis and Characterization of Biodegradable Thiolated Chitosan Nanoparticles as Targeted Drug Delivery System. J Nanomedic Nanotechnol S4:001. doi:10.4172/2157-7439.S4001

Copyright: ( 2011 Saboktakin MR, et al. This is an open-access article distributed under the terms of the Creative Commons Attribution License, which permits unrestricted use, distribution, and reproduction in any medium, provided the original author and source are credited. 
Citation: Saboktakin MR, Tabatabaie RM, Maharramov A, Ramazanov MA (2011) Synthesis and Characterization of Biodegradable Thiolated Chitosan Nanoparticles as Targeted Drug Delivery System. J Nanomedic Nanotechnol S4:001. doi:10.4172/2157-7439.S4001

the polymer surface. Spectra were obtained in the wave number range of $400-4000 \mathrm{~cm}^{-1}$. Spectra of samples were recorded from $\mathrm{KBr}$ in 1:10 $(\mathrm{wt} / \mathrm{wt})$ ratio. The amount of released drug was determined on a Philips PU 8620 UV spectrophotometer.

\section{Synthesis of TCS}

The chemical modification of CS was performed as previously described. CS (500 mg) was dissolved in $50 \mathrm{~mL}$ of $1 \%$ acetic acid. In order to facilitate reaction with thioglycolic acid (TGA), $100 \mathrm{mg}$ of ethyl-3-(3-dimethylaminopropyl) carbodiimide hydrochloride (EDAC) was added to the chitosan solution. After EDAC was dissolved, $30 \mathrm{~mL}$ of TGA was added and the $\mathrm{P}^{\mathrm{H}}$ was adjusted to 5.0 with $3 \mathrm{~N} \mathrm{NaOH}$. The reaction mixture was stirred and left for $3 \mathrm{~h}$ at room temperature. To eliminate the unbounded TGA and to isolate the polymer conjugates, the reaction mixture was dialyzed against 5 $\mathrm{mM} \mathrm{HCl}$ five times (molecular weight cut-off $10 \mathrm{kDa}$ ) over a period of 3 days in the dark, then two times against $5 \mathrm{mM} \mathrm{HCl}$ containing $1.0 \%$ $\mathrm{NaCl}$ to reduce ionic uninteractions between the cationic polymer and the anionic sulfhydryl compound.

\section{LTZ Loading}

TCS $(0.2 \mathrm{~g})$ was dissolved in $15 \mathrm{~mL} 1 \% \mathrm{vol} / \mathrm{vol}$ acetic acid containing $4 \%$ glycerine. For the loading of LTZ into polymeric matrix, $0.24 \mathrm{~g} \mathrm{LTZ}$ was suspended in the mixture. Before the addition of nanoparticles, a $200 \mu \mathrm{l}$ sample was taken and filtered using a low protein binding 0.22 $\mu \mathrm{m}$ PVDF filter (Millipore, Bedford, MA) and then replaced with equal amounts of $1 \times \mathrm{PBS}, \mathrm{P}^{\mathrm{H}}$ 7.4. An additional sample was taken in the same manner after loading. The particles were collapsed using $10 \mathrm{~mL}$ $0.1 \mathrm{~N} \mathrm{HCl}$, filtered with Whattman Grade 4 filter paper, and washed with $20 \mathrm{~mL}$ of deionized water. After filtering, particles were frozen in a $-80^{\circ} \mathrm{C}$ freezer and lyophilized at $-50^{\circ} \mathrm{C}$ under vacuum (LabConco Model 77500) for 24 hours.

\section{SEM characterization}

TCS - LTZ nanoparticles were prepared as previously described and kept in a dry environment until imaging. The nanoparticles were sprinkled onto an aluminum stub that was covered with carbon tape. Excess nanoparticles were removed by gently tapping the stub and the samples were sputtered coated with a gold layer between 5 and $10 \mathrm{~nm}$ thick. Samples were imaged with a SEM (Philips XL-30 E) at $10 \mathrm{kV}$ and a working distance of $7 \mathrm{~mm}$.

\section{Fourier Transform Infra-Red Spectroscopy (FT-IR) Study}

The Fourier transform infrared analysis was conducted to verify the possibility of chemical bonds between drug and polymer. Samples of pure LTZ and LTZ-TCS nanoparticles were scanned in the IR range from $400-4000 \mathrm{~cm}^{-1}$ with carbon black as reference. The detector was purged carefully by clean dry helium gas to increase the signal level and reduce moisture.

\section{Particle size}

After drying at $37^{\circ} \mathrm{C}$ for 48 hours, the mean diameter of the dried nanoparticle was determined by a sieving method using USP standard sieves. Observations are recorded.

\section{Drug content and Entrapment Efficiency (EE)}

Drug entrapment efficiency (EE) was determined by centrifuging (with Centrifuge-3K30, Sigma Laboratory) aqueous dispersion of LTZTCS nanoparticles at $25,000 \mathrm{rpm}, 5^{\circ} \mathrm{C}$ for $25 \mathrm{~min}$ and measuring the amount of LTZ in the supernatant with the help of double beam UV-
VIS Spectrophotometer (Philips PU 8620,USA), set at $238 \mathrm{~nm}$. The amount of LTZ was subtracted from initial amount of LTZ taken to calculate drug entrapment efficiency of nanoparticles. The experiment was performed in triplicate for each batch and average drug entrapment efficiency was calculated.

\section{In vitro release study}

In vitro release study of LTZ-TCS nanoparticles was conducted in Franz Diffusion Cell. The diffusion cell model adapted to the spectrophotometer cuvette, with $1 \mathrm{~cm}$ of optic way and $1 \mathrm{~mL}$ of volume, was used for the in vitro release of LTZ. A cellulose acetate membrane (Dialysis membrane with Molecular weight cut off value of 5,000 10,000 , Himedia-60) was adapted to the terminal portion of the glass cylinder of the Franz Diffusion cell by a rubber ring. mL of LTZ-TCS nanoparticles aqueous dispersion was loaded to cylinder and coupled to the diffusion cell containing the receptor phase $(60 \mathrm{~mL}$ of $0.2 \mathrm{M}$ Phosphate buffer solution $\mathrm{P}^{\mathrm{H}} 7.4$ ) at $37^{\circ} \mathrm{C}$. The dissolution media was agitated at $25 \mathrm{rpm}$ using magnetic stirrer. At different time intervals, aliquots of $2 \mathrm{~mL}$ were withdrawn and immediately restored with same volume of fresh Phosphate buffer. The amount of LTZ released was assessed by double beam UV spectrophotometer (Philips PU 8620, USA) set at $238 \mathrm{~nm}$ versus a calibration curve prepared in the same buffer.

\section{Statistical analysis}

Experimental data have been represented as the mean with standard deviation (SD) of different independent determinations.

(a)

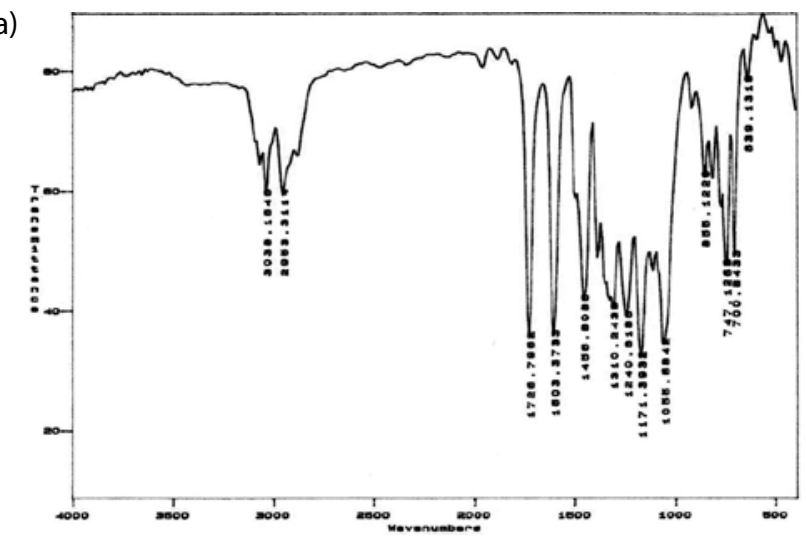

(b)

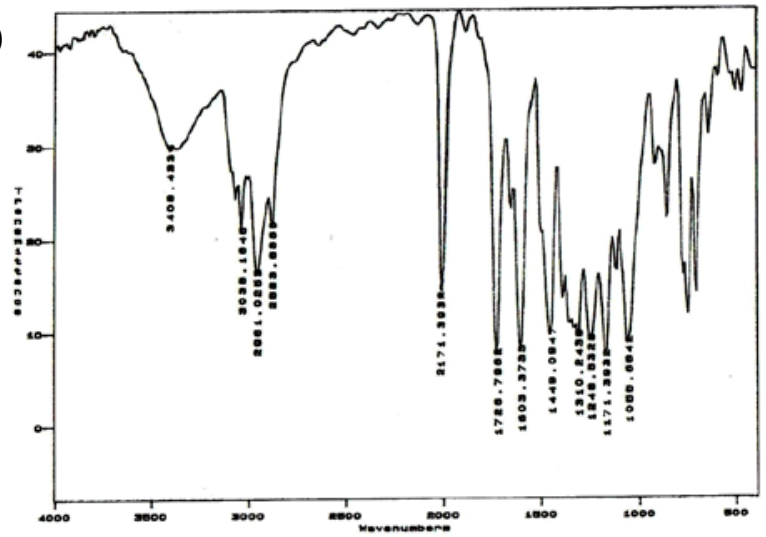

Figure 1: FT-IR spectra of a) Pure thiolated chitosan b) Letrozloe loaded thiolated chitosan (TCS) nanoparticles. 
Citation: Saboktakin MR, Tabatabaie RM, Maharramov A, Ramazanov MA (2011) Synthesis and Characterization of Biodegradable Thiolated Chitosan Nanoparticles as Targeted Drug Delivery System. J Nanomedic Nanotechnol S4:001. doi:10.4172/2157-7439.S4001

Page 3 of 4
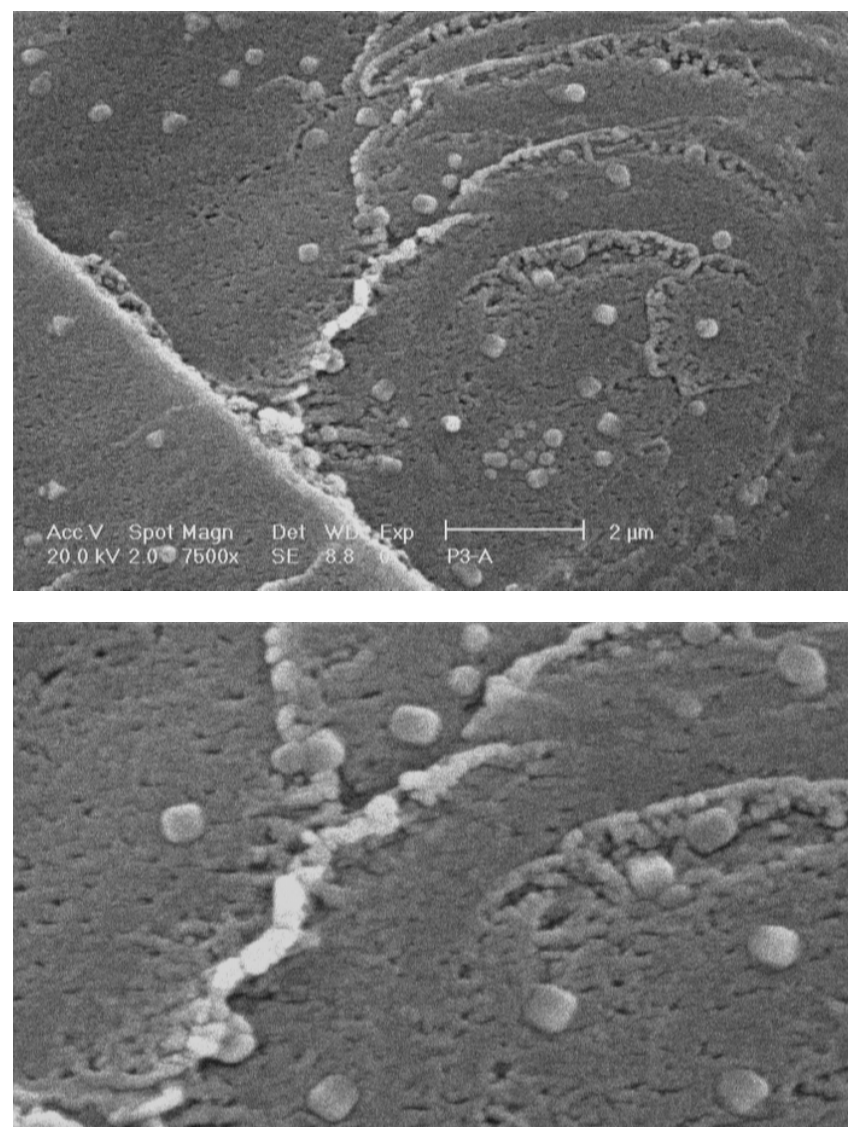

Figure 2: SEM photomicrograph of thiolated chitosan nanoparticles loaded with Letrozole drug.

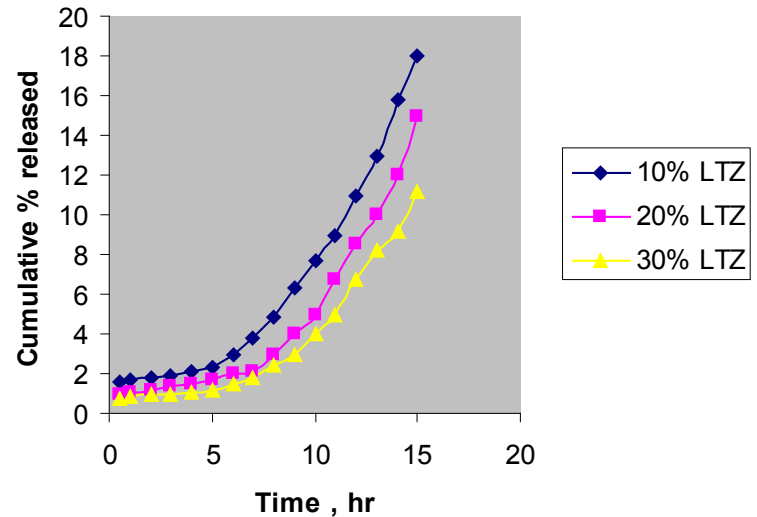

Figure 3: In vitro release data of LTZ-TCS nanoparticles.

The significance of differences was evaluated by analysis of variance (ANOVA). Differences were considered statistically significant at $\mathrm{P}<$ 0.005 .

\section{Results and Discussion}

\section{Fourier Transform Infra-Red spectroscopy (FT-IR) study}

The synthesized polymer was characterized by IR spectroscopy. The FT-IR spectrum of LTZ- TCS is shown in Figure 1. In the spectra of TCS $-\mathrm{OH}$ and $-\mathrm{NH}$ stretch were clearly seen at 3038.185 and 2961.025 $\mathrm{cm}^{-1}$, respectively. Additional presences of amidine I and amidine II bands are seen at 1725.786 and $1603.373 \mathrm{~cm}^{-1}$ corresponding to $\geq \mathrm{NH}_{2}{ }^{+}$ stretch and $\mathrm{NH} \geq \mathrm{NH}_{2}^{+}$, respectively, being two coupled vibrations. The presence of an additional band at 1495.3783 and $1449.0847 \mathrm{~cm}^{-1}$ can be assigned for N-H band of the salt $\mathrm{NH}_{2}{ }^{+} \mathrm{Cl}$. Other characteristic peaks of CS O-H stretch, C-H stretch and C-O stretch were present at $3400-3600,2930$, and $1009-1171 \mathrm{~cm}^{-1}$, respectively. This confirmed the synthesis of TCS. The spectrum of TCS was well correlated with reports by Matsuda et al. for TCS. Thiol content of TCS was found $214 \pm 52$ $\mu \mathrm{mol} / \mathrm{g}$.

\section{SEM characterization}

The morphology of nanoparticles was examined by scanning electron microscopy (SEM, Philips XL-30 E, USA). The nanoparticles were mounted on metal stubs using double - sided tape and coated with a $150 \mathrm{~A}^{\circ}$ layer of gold under vacuum. S tubes were visualized under scanning electron microscope. Figure 2 shows the SEM of LTZ-TCS nanoparticles that synthesized by chemical reaction. These nanoparticles are very sensitive to the temperature that due to the interaction electron and sample. Scanning electron micrography images were obtained from a diluted solution of the LTZ particle. The white spots are LTZ nanoparticles. The SEM image shows the presence of LTZ spherical particles in polymer matrix, which are homogeneously, distributed throughout the polymer, which is also confirmed from ${ }^{1} \mathrm{H}$-NMR studies. As observed from SEM photomicrographs, the crystals of LTZ have a different appearance than recrystallized LTZ. These nanoparticles do not have clearly defined crystal morphological features in the SEM photomicrographs.

\section{Drug content and Entrapment Efficiency (EE)}

It has been reported that the encapsulation efficiency of LTZ-TCS nanoparticles increases from about $68.5 \%$ to $87.2 \%$ with the increment of their mean diameter from $64 \mathrm{~nm}$ to $255 \mathrm{~nm}$ (Table 1). The lower encapsulation efficiencies obtained with the smaller particles could be explained by the longer surface area of smaller droplets for a given volume of organic phase. Hence, during the emulsification step, a more direct contact between internal and external phases occurred, resulting in a higher drug loss by diffusion towards the external medium.

\section{In vitro release studies +}

Batches of three different compositions (10\%, 20\%, and 30\% of LTZ) were studied and the results of cumulative percentage released over 15 hours were shown in Figure 3. The results showed that there was a pronounced time prolongation of drug release from LTZ-TCS nanoparticles. Batch with 10\% LTZ showed the slowest release and batch with 30\% LTZ showed highest release. Formulation (30\% drug) with highest LTZ entrapment (86.32\%) showed highest drug release rate and cumulative drug release while formulation with $10 \%$ drug and lowest LTZ entrapment increases the amount of drug close to the surface as well as the drug in the core from nanoparticles.Thus the difference in drug release profiles of three batches of LTZ-TCS nanoparticles can be explained. Drug release from LTZ-TCS nanoparticles takes place by

\begin{tabular}{|l|l|l|l|}
\hline $\begin{array}{l}\text { Formulation Drug } \\
\text { (wt\% of polymer) }\end{array}$ & $\begin{array}{l}\text { Encapsulation } \\
\text { Efficiency }(\%)\end{array}$ & $\begin{array}{l}\text { Mean diameter } \\
\text { (nm) }\end{array}$ & $\begin{array}{l}\text { Poly-dispersity } \\
\text { index }\end{array}$ \\
\hline Blank & - & $60.4 \pm 25.0$ & $0.27 \pm 0.01$ \\
\hline 10 & $68.50 \pm 0.52$ & $64.0 \pm 15.0$ & $0.36 \pm 0.05$ \\
\hline 20 & $76.12 \pm 3.6$ & $145.9 \pm 40.2$ & $0.45 \pm 0.01$ \\
\hline 30 & $87.20 \pm 4.0$ & $255.3 \pm 40.5$ & $0.68 \pm 0.10$ \\
\hline
\end{tabular}

Table 1: Characterization of blank and LTZ-TCS nanoparticles. 
Citation: Saboktakin MR, Tabatabaie RM, Maharramov A, Ramazanov MA (2011) Synthesis and Characterization of Biodegradable Thiolated Chitosan Nanoparticles as Targeted Drug Delivery System. J Nanomedic Nanotechnol S4:001. doi:10.4172/2157-7439.S4001

Page 4 of 4

several mechanisms including surface and bulk erosion, disintegration, diffusion, and desorption. In this study, release of drug from TCS matrix has been found to occur predominantly by its diffusion from the polymer matrix. During the later phases, the release is mediated through both diffusion of therapeutic agent and degradation of polymer matrix itself.

\section{Conclusions}

The results of present study revealed that LTZ can be entrapped into TCS nanoparticles, which can provide sustained drug release with high drug entrapment efficiency. The nanoparticles were successfully developed by emulsion/solvent evaporation method resulting in smaller mean particle size range. Size distribution, entrapment efficiency, release characteristics were influenced by drug to polymer ratio in formulation. Hence, nanoparticles of LTZ prepared from TCS may represent a useful approach for targeting its release at its site of absorption, sustaining its release and improving its oral availability.

\section{References}

1. Liu WC, Yao KD (2002) Chitosan and its derivatives-a promising non-viral vector for gene transfection. Journal of Control Release 83: 1-11.

2. Synder GH, Ready MK, Cennerazzo MJ, Field D (1983) Use of local electrostatic environments of cysteines to enhance formation of a desired species in a reversible disulfide exchange reaction. Journal of Biochemical Biophysical Acta 749: 219-226.

3. Thanou M, Nihot MT, Jansen M, Verhoef JC, Junginger HE (2001) Mono-Ncarboxymethyl chitosan (MCC), a polyampholytic chitosan derivative, enhances the intestinal absorption of low molecular weight heparin across intestinal epithelia in vitro and in vivo. Journal of Pharmaceutical Sciences 90: 38-46.

4. Geisler J, Helle H, Ekse D, Duong NK, Evans DB, et al. (2008) Letrozole is superior to anastrozole in suppressing breast cancer tissue and plasma estrogen levels. Journal of Clinical Cancer Research 14: 6330-6335.

5. Bibby DC, Talmadge JE, Dalal MK, Kurz SG, Chytil KM, et al. (2005) Pharmacokenetics and biodistribution of RGD-targeted doxorubicin loaded nanoparticles in tumor-bearing mice. International Journal of Pharmaceutics 293: 281-290.

6. Andreas BS, Hopf TE (2001) Synthesis and in vitro evaluation of chitosanthioglycolic acid conjugates. Journal of Science pharmacy 69: 109-118.

7. Hornof MD, Kast CE, Andreas BS (2003) In vitro evaluation of the viscoelastic behavior of chitosan-thioglycolic acid conjugates. European Journal of Pharmaceutical Biopharmaceutics 55: 185-190.

8. Andreas BS, Hornof M, Zoidl T (2003) Thiolated polymers-thiomers: modification of chitosan with 2-iminothiolane. International Journal of Pharmaceutics 260: 229-237.

9. Roldo M, Hornof M, Caliceti P, Andreas BS (2004) Mucoadhesive thiolated chitosans as platforms for oral controlled drug delivery: synthesis and in vitro evaluation. European Journal of Pharmaceutical Biophamaceutics 57: 115-121.

10. Langoth N, Guggi D, Pinter Y, Andreas BS (2004) Thiolated chitosan: in vitro evaluation of its permeation properties. Journal of Control Release 94: 177186.

11. Kast CE, Valenta C, Leopold M, Andreas BS (2002) Design and in vitro evaluation of a novel bioadhesive vaginal drug delivery system for clotrimazole. Journal of Control Release 81: 347-354

12. Leitner VM, Marschutz MK, Andreas BS (2003) Mucoadhesive and cohesive properties of poly (acrylic acid)-cysteine conjugates with regard to their molecular mass. European Journal of Pharmaceutical Sciences 18: 89-96.

13. Senel S, Kremer M, Kas S, Wertz PW, Hincal AA, et al. (2000) Enhancing effect of chitosan on peptide drug delivery across buccal mucosa. Journal of Biomaterials 21: 2067-2071.

14. Mondal N, Pal TK, Ghosal SK (2008) Development, physical characterization micromeritics and in vitro release kinetics of letrozole loaded biodegradable nanoparticles. Pharmazie 63: 361-365.

15. Felt O, Buri P, Gurny R (1998) Chitosan: a unique polysaccharide for drug delivery. Journal of Drug Development and Industrial Pharmacy 24: 979-993.

16. Kast CE, Frick W, Losert U, Andreas BS (2003) Chitosan -thioglycolic acid conjugate: a new scaffold material for tissue engineering. International Journal of Pharmaceutics 256: 183-186.

17. Leroux JC, Allemann E, Jaeghere FD, Doelker E, Gurny R (1996) Biodegradable nanoparticles from sustained release formulations to improved site specific drug delivery. Journal of Control Release 39: 339-350.

18. Coppi G, Lannuccelli V, Leo E, Bernabei MT, Cameroni R (2001) Chitisanalginate microparticles as a protein carrier. Journal of Drug Development and Industrial Pharmacy 27: 393-400.

19. Guggi D, Kast CE, Andreas BS (2003) In vivo evaluation of an oral calcitonin delivery system for rats based on a thiolated chitosan matrix. Journal of Pharmaceutical Research 20: 1989-1994.

20. Bromberg LE (2001) Enhanced nasal retention of hydrophobically modified polyelectrolytes. Journal of Pharmacy and Pharmacology 53: 109-114. 